\title{
Separation of Rhenium from Lead-Rich Molybdenite Concentrate via Hydrochloric Acid Leaching Followed by Oxidative Roasting
}

\author{
Guanghui Li, Zhixiong You ${ }^{*}{ }^{\dagger}$, Hu Sun, Rong Sun, Zhiwei Peng ${ }^{*}{ }^{\dagger}$, Yuanbo Zhang and Tao Jiang \\ School of Minerals Processing \& Bioengineering, Central South University, Changsha 410083, China; \\ liguangh@csu.edu.cn (G.L.); sunhusunhu@csu.edu.cn (H.S.); sunrongcsu@163.com (R.S.); \\ zybcsu@126.com (Y.Z.); jiangtao@csu.edu.cn (T.J.) \\ * Correspondence: yzx445474096@126.com (Z.Y.); zwpeng@csu.edu.cn (Z.P.); \\ Tel.: +86-731-888-30542 (Z.Y. \& Z.P.) \\ + These authors contributed equally to this work.
}

Academic Editor: Hugo F. Lopez

Received: 12 October 2016; Accepted: 13 November 2016; Published: 16 November 2016

\begin{abstract}
Lead-rich molybdenite is a typical rhenium-bearing molybdenum resource in China, which has not been efficiently utilized due to its high contents of lead and gangue minerals. In this study, hydrochloric acid was used for preliminarily removing lead and calcite from a lead-rich molybdenite concentrate. Oxidative roasting-ammonia leaching was then carried out for separation of rhenium and extraction of molybdenum. The hydrochloric acid leaching experiments revealed that $93.6 \% \mathrm{~Pb}$ and $97.4 \% \mathrm{Ca}$ were removed when the leaching was performed at $95^{\circ} \mathrm{C}$ for $10 \mathrm{~min}$ with $\mathrm{HCl}$ concentration of $8 \mathrm{wt}$. \% and liquid-solid ratio of $5(\mathrm{~mL} / \mathrm{g})$. The results of direct oxidative roasting indicated that $89.3 \%$ rhenium was volatilized from the raw concentrate after roasting at $600{ }^{\circ} \mathrm{C}$ for $120 \mathrm{~min}$ in air. In contrast, the rhenium volatilization was enhanced distinctly to $98.0 \%$ after the acid-leached concentrate (leaching residue) was roasted at $550{ }^{\circ} \mathrm{C}$ for $100 \mathrm{~min}$. By the subsequent ammonia leaching, $91.5 \%$ molybdenum was leached out from the calcine produced from oxidative roasting of the acid-leached concentrate, while only $79.3 \%$ Mo was leached from the calcine produced by roasting molybdenite concentrate without pretreatment.
\end{abstract}

Keywords: molybdenite concentrate; rhenium; lead; oxidative roasting; acid leaching

\section{Introduction}

Rhenium $(\mathrm{Re})$ is an important metal that has been widely used in many fields, such as national defense, petrochemical engineering, aerospace, photovoltaics, solar cells, etc [1]. The global Re resource reached 2.5 million $\mathrm{kg}$ with only $48,800 \mathrm{~kg}$ produced in 2014 . More than half of the production was from Chile, which has more than 1.3 million $\mathrm{kg}$ Re in reserves [2]. Rhenium is a rare metal occurring as rheniite $\left(\operatorname{ReS}_{2}\right)$ mainly accompanying molybdenite. It was also found in some copper, niobium yttrium iron, platinum and uranium ores. Typically, copper or molybdenum sulfide concentrates via flotation circuits contain 50-100 g/t (ppm) Re [3]. Because of the high value of rhenium, recovering rhenium from molybdenum concentrate has received much attention.

During the roasting process of molybdenite concentrate, rhenium is volatized and enters the gas phase as $\mathrm{Re}_{2} \mathrm{O}_{7}$. A small portion may remain with the calcine. There are two types of roasting: oxidative roasting and solidification roasting [4]. The former process recovers molybdenum by leaching the calcine in ammonium hydroxide to produce ammonium molybdate. The contained rhenium is separated and volatilized into dust in the form of oxides $\left(\operatorname{Re}_{2} \mathrm{O}_{7}\right)$, which are soluble in water or hydrogen peroxide solutions [5]. In solidification roasting, both rhenium and molybdenum 
are retained in calcine in the presence of slaked lime [6] or soda ash [7]. Rhenium is then extracted by leaching the lime-roasted calcine in sulfuric acid or water [6]. A common problem with the solidification roasting method is attributed to the large amount of slaked lime added, which would lower the contents of molybdenum and rhenium and prolong the enrichment period, exerting an unfavorable effect on the recovery of rhenium. Unlike lime-roasting, the molybdenum and rhenium in soda ash-roasted calcine could be leached in water solution [8].

Molybdenum and rhenium can be simultaneously leached by pressure oxidation leaching (POX), which is divided into two types: acid pressure leaching [9-11] and alkaline pressure leaching according to the leaching medium [12]. The use of high pressure and high concentration acid or alkali corroded the equipment severely. These two metals can also be extracted by other approaches, such as electrochemical leaching [13,14], bioleaching [15,16] and microwave-assisted leaching [17], although they have not been utilized commercially. The current industrial practice in the recovery of rhenium from rhenium-bearing solutions was generally conducted through ion exchange or solvent extraction [18-21].

Up to now, oxidative roasting has widely been used around the world by large manufacturers because of its low cost, easy operation and high efficiency [22,23]. However, the formation of molybdate and sulfate due to the existence of sulfides $\left(\mathrm{PbS}, \mathrm{FeS}, \mathrm{ZnS}\right.$ and $\mathrm{Cu}_{2} \mathrm{~S}$ ) often restrains the recovery of molybdenum [24]. Moreover, the reactions between gangue minerals and molybdite would result in serious sintering, which restricts the oxidation of molybdenite and volatilization of rhenium [25]. Previous studies mainly focused on the behavior of molybdenum during the roasting [26,27], but few studies explored the behaviors of rhenium and the gangue minerals in favor of separating rhenium from molybdenum. The volatilization behavior of rhenium and roasting characteristics of molybdenum concentrate deserve further attention.

Lead-rich molybdenite is a typical molybdenum resource in Shanxi province of China, which has not been efficiently utilized mainly due to its high lead content [28]. The successful roast-leach process should volatilize rhenium as much as possible but simultaneously reduce the volatilization of molybdenum, leaving a negligible effect on the subsequent ammonium leaching process. In view of the high lead content in the raw material, hydrochloric acid was adopted to initially remove lead and calcite in this study [29]. The effects of leaching parameters on the removal of lead and the separation of rhenium during subsequent oxidative roasting were examined. Eventually, molybdenum was leached from the calcine in the ammonium solution to identify the favorable effect of $\mathrm{HCl}$ leaching.

\section{Experimental Section}

\subsection{Materials}

The lead-rich molybdenite concentrate sample was obtained from a dressing plant of Shanxi province, China. The size distribution of the sample was $95.2 \mathrm{wt}$. \% of the particles smaller than $0.074 \mathrm{~mm}$. The main chemical composition of the sample is shown in Table 1 . The Mo and Re contents were $43.55 \mathrm{wt}$. \% and $321 \mathrm{~g} / \mathrm{t}$, respectively, and the lead content was as high as $4.52 \mathrm{wt}$. \%. The XRD pattern shown in Figure 1 indicates that molybdenum mainly existed in the form of molybdenite $\left(\mathrm{MoS}_{2}\right)$ and the gangue minerals were galena $(\mathrm{PbS})$, quartz $\left(\mathrm{SiO}_{2}\right)$ and a small amount of calcite $\left(\mathrm{CaCO}_{3}\right)$.

The gases for oxidative roasting and cooling were mixed $\mathrm{O}_{2} / \mathrm{N}_{2}$ and $\mathrm{N}_{2}$ gases, respectively. The purity of these gases was above $99.99 \%$.

Table 1. Main chemical composition of lead-rich molybdenite concentrate/wt. \%.

\begin{tabular}{lcccccccccc}
\hline $\mathrm{Mo}$ & $\mathrm{Re}$ & $\mathrm{Fe}$ & $\mathrm{SiO}_{\mathbf{2}}$ & $\mathrm{Al}_{2} \mathbf{O}_{3}$ & $\mathrm{CaO}$ & $\mathrm{MgO}$ & $\mathrm{WO}_{3}$ & $\mathrm{Cu}$ & $\mathrm{Pb}$ & $\mathbf{S}$ \\
\hline 43.55 & $321 \mathrm{~g} / \mathrm{t}$ & 1.39 & 4.02 & 0.18 & 3.27 & 0.48 & 1.66 & 0.03 & 4.52 & 32.46 \\
\hline
\end{tabular}




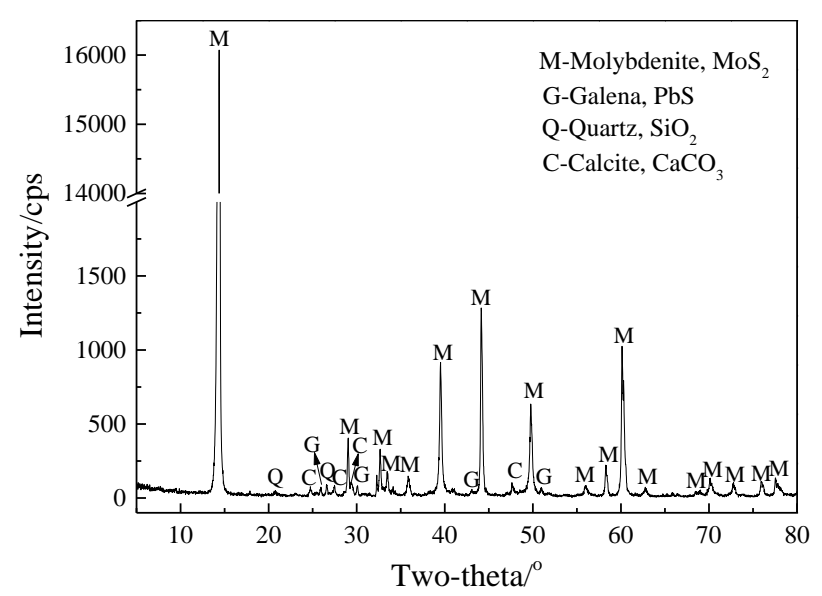

Figure 1. XRD pattern of the lead-rich molybdenum concentrate.

\subsection{Experimental Procedure}

The experimental procedure mainly included acid leaching, drying, oxidative roasting, cooling, etc. In each leaching test, $5 \mathrm{~g}$ of the sample was treated in a beaker containing a predetermined quantity of hydrochloric acid (determined according to the liquid-solid ratio $(\mathrm{mL} / \mathrm{g})$. The beaker was located in a water bath that maintains the leaching temperature with a solution stirred continuously. After leaching for a desired duration, the solution was filtered and the residue obtained was washed with hot distilled water and dried for chemical analysis.

The samples after hydrochloric acid leaching (acid-leached concentrate) were balled into green pellets with 10-14 mm in diameter. The pellets were dried in an oven at $80^{\circ} \mathrm{C}$ for $4 \mathrm{~h}$ before oxidative roasting. The schematic diagram of the roasting apparatus is shown in Figure 2. The dried pellets were firstly loaded into the reactor (a quartz tube with perforated screen plate at the bottom), into which the nitrogen gas was flushed to expel the air. Then, the quartz tube was transferred into the heating zone of an electric resistance furnace that was preheated at a rate of $10{ }^{\circ} \mathrm{C} / \mathrm{min}$ to a required temperature. The mixed $\mathrm{O}_{2} / \mathrm{N}_{2}$ gases were directed into the tube immediately. The composition of oxidative gas was adjusted by the flowmeters of $\mathrm{O}_{2}$ and $\mathrm{N}_{2}$, and the total flow rate was fixed at $4.0 \mathrm{~L} / \mathrm{min}$ to ensure reaction atmosphere. After roasting for a certain time period, the quartz tube was taken out of the furnace and cooled down in $\mathrm{N}_{2}$. The calcine was then collected for analysis.

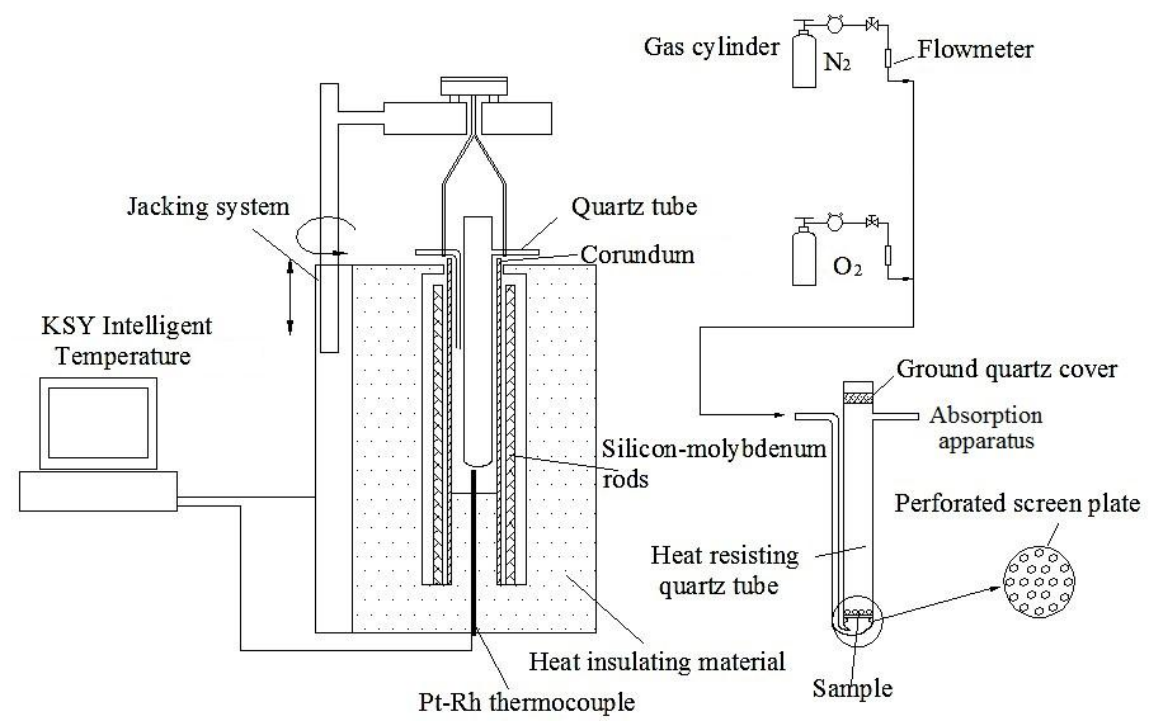

Figure 2. Schematic diagram of the equipment for roasting. 


\subsection{Analytical Method}

The XRD analysis was conducted using a diffractometer (RIGAKU D/Max 2500, Akishima, Japan) under the conditions as follows: $\mathrm{Cu} \mathrm{K} \alpha$, tube current and voltage: $250 \mathrm{~mA}, 40 \mathrm{kV}$, scanning range: $10^{\circ}-80^{\circ}(2 \theta)$, step size: $0.02^{\circ}(2 \theta)$ and scanning speed: $8^{\circ} / \mathrm{min}$.

The contents of $\mathrm{Pb}$ and Mo were measured by the chemical titration method, while the Re content was assayed by the instrument of Inductively Coupled Plasma Optical Emission Spectrometer (ICP-OES, Thermo Scientific iCAP 7000 series, Waltham, MA, USA).

The acidic leaching ratio of $\mathrm{Pb}, \mathrm{Mo}$ or Re was calculated by the equation as follows:

$$
\beta=\left(1-\frac{m_{1} \times \varepsilon_{1}}{m_{0} \times \varepsilon_{0}}\right) \times 100 \%
$$

where $\beta$ is the leaching ratio, $\% ; m_{0}$ is the weight of molybdenite concentrate, $g ; \varepsilon_{0}$ is the weight fraction of $\mathrm{Pb}, \mathrm{Mo}$ or Re of molybdenite concentrate, $\% ; m_{1}$ is the weight of leached residue, g; and $\varepsilon_{1}$ is the $\mathrm{Pb}, \mathrm{Mo}$ or Re weight fraction of leached residue, \%.

The volatilization ratio of Mo or Re was calculated according to the following equation:

$$
\alpha=\left(1-\frac{m_{2} \times \varepsilon_{2}}{m_{0} \times \varepsilon_{0}}\right) \times 100 \%
$$

where $\alpha$ is the volatilization ratio (\%); $m_{0}$ is the weight of molybdenite concentrate, $g ; \varepsilon_{0}$ is the Mo or Re weight fraction of molybdenite concentrate, $\% ; m_{2}$ is the weight of roasted product, g; and $\varepsilon_{2}$ is the weight fraction of Mo or Re of roasted product, $\%$.

\section{Results and Discussion}

\subsection{Removal of $\mathrm{Pb}$ by Acid Leaching with $\mathrm{HCl}$}

\subsubsection{Chemistry of $\mathrm{HCl}$ Leaching}

In $\mathrm{HCl}$ solution, galena is capable of being selectively removed due to its high solubility. Conversely, molybdenite remains chemically stable. Traditional processes of removing galena from molybdenite concentrate with $\mathrm{HCl}$ are carried out in the presence of $\mathrm{CaCl}_{2}$ or $\mathrm{NaCl}$ [28]. Due to the existence of $\mathrm{CaCO}_{3}$ (Table 1) in the raw concentrate, the newly formed $\mathrm{CaCl}_{2}$ may facilitate the dissolution of $\mathrm{PbCl}_{2}$. Thus, no additional $\mathrm{CaCl}_{2}$ is needed during acid leaching. The chemical reactions can be described by the following equations:

$$
\begin{gathered}
\mathrm{CaCO}_{3}+2 \mathrm{HCl} \rightarrow \mathrm{CaCl}_{2}+\mathrm{CO}_{2}+\mathrm{H}_{2} \mathrm{O} \\
\mathrm{PbS}+2 \mathrm{HCl} \rightarrow \mathrm{PbCl}_{2}+\mathrm{H}_{2} \mathrm{~S} \\
\mathrm{PbCl}_{2}+2 \mathrm{Cl}^{-} \rightarrow\left[\mathrm{PbCl}_{4}\right]^{2-}
\end{gathered}
$$

During the acid leaching, calcite is easily dissolved (Equation (3)) and galena will react with hydrochloric acid to form lead chloride (Equation (4)). The lead chloride is soluble in hot water, and its solubility is improved distinctly in $\mathrm{CaCl}_{2}$ solution by forming a complex compound (Equation (5)). As a result, the galena and calcite can be effectively removed and lead chloride is expected to be recovered by cooling the leachate [30].

\subsubsection{Effect of $\mathrm{HCl}$ Concentration}

The effect of hydrochloric acid concentration on the removal of $\mathrm{Pb}$ was investigated by keeping leaching temperature at $95^{\circ} \mathrm{C}$, leaching time of $10 \mathrm{~min}$ and liquid-solid ratio of $5(\mathrm{~mL} / \mathrm{g})$. The results are plotted in Figure 3. It can be observed that lead was not effectively removed until the hydrochloric acid concentration was higher than 6 wt. \%. By increasing the $\mathrm{HCl}$ concentration from $1 \mathrm{wt}$. \% to 
6 wt. \%, the removal of $\mathrm{Pb}$ increaseddramatically from $23.4 \%$ to $92.5 \%$, and then it remained almost constant. During the acid leaching, hydrochloric acid is not only used to remove galena, but also exhausted by $\mathrm{CaCO}_{3}, \mathrm{MgCO}_{3}$ as well as other sulfides. The $\mathrm{HCl}$ concentration required for leaching galena is actually a small part. The stoichiometric threshold of $\mathrm{HCl}$ concentration for removing the majority of $\mathrm{Pb}, \mathrm{Ca}, \mathrm{Mg}$ and part of $\mathrm{Fe}$ is about $1.5 \%-2 \%$. As observed from Figure 3, the dramatic increase in $\mathrm{Pb}$ extraction is 2-3 times the stoichiometric threshold. Meanwhile, the leaching ratio of molybdenum increased gradually to its maximum value of $1.7 \%$ as the $\mathrm{HCl}$ concentration was increased to $6 \mathrm{wt}$. \%. A further increase in $\mathrm{HCl}$ concentration lowers the leaching ratio of molybdenum. In contrast, the leaching ratio of rhenium kept increasing with $\mathrm{HCl}$ concentration. The suitable $\mathrm{HCl}$ concentration was $8 \mathrm{wt}$. \%.

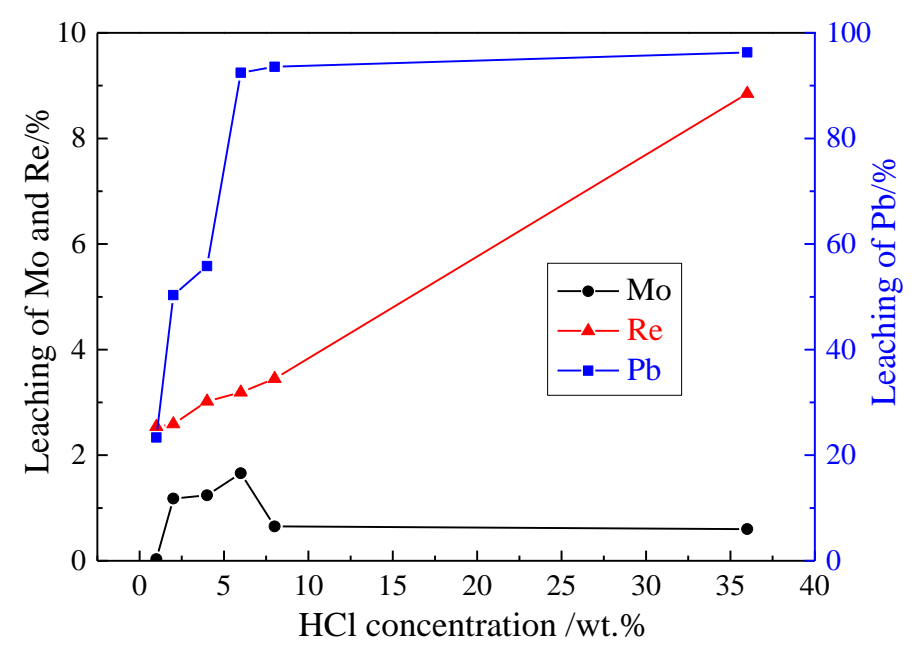

Figure 3. Effect of $\mathrm{HCl}$ concentration on the leaching of $\mathrm{Mo}$, Re and $\mathrm{Pb}$.

\subsubsection{Effect of Leaching Temperature}

By fixing the $\mathrm{HCl}$ concentration at $8 \mathrm{wt}$. \%, leaching time at $10 \mathrm{~min}$ and liquid-solid ratio at $5(\mathrm{~mL} / \mathrm{g})$, the effect of leaching temperature on the removal of lead and leaching of molybdenum and rhenium was examined, as shown in Figure 4. As the leaching temperature was increased, the reaction between galena and hydrochloric acid was accelerated and the solubility of $\mathrm{PbCl}_{2} \mathrm{was}$ improved. The leaching ratios of $\mathrm{Pb}$ and Re increased gradually from $24.5 \%$ and $0.5 \%$ to $93.6 \%$ and $3.6 \%$, respectively, when the leaching temperature was increased from $25{ }^{\circ} \mathrm{C}$ to $95{ }^{\circ} \mathrm{C}$. In addition, the little Mo was extracted in this regard, and the appropriate leaching temperature was $95^{\circ} \mathrm{C}$.

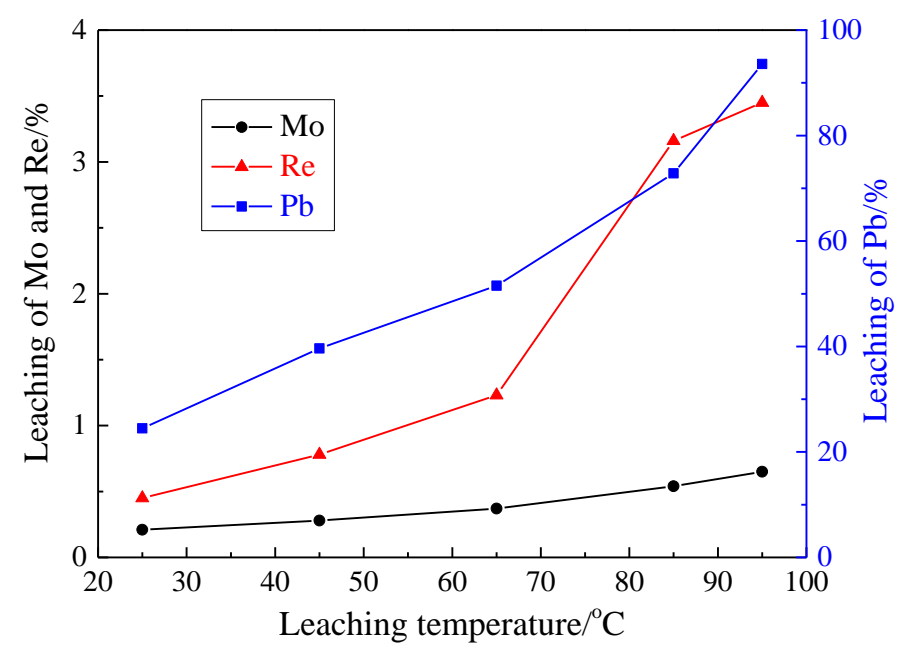

Figure 4. Effect of leaching temperature on the leaching of $\mathrm{Mo}$, Re and $\mathrm{Pb}$. 


\subsubsection{Effect of Leaching Time}

The effect of leaching time on the removal of $\mathrm{Pb}$ was studied under the following conditions: $\mathrm{HCl}$ concentration of $8 \mathrm{wt}$. \%, leaching temperature of $95{ }^{\circ} \mathrm{C}$ and liquid-solid ratio of $5(\mathrm{~mL} / \mathrm{g})$. The results plotted in Figure 5 indicate that $85.5 \%$ of $\mathrm{Pb}$ was leached in only 2 min, and this number increased gradually to $93.6 \%$ in $10 \mathrm{~min}$. The variation of Re was similar to that of $\mathrm{Pb}$, which increased from $0.6 \%$ to $3.6 \%$ within the time range of 2-10 min. However, the leaching ratio of Mo changed slightly when the leaching time was prolonged to $60 \mathrm{~min}$. Hence, leaching time of $10 \mathrm{~min}$ was sufficient for removing the majority of lead.

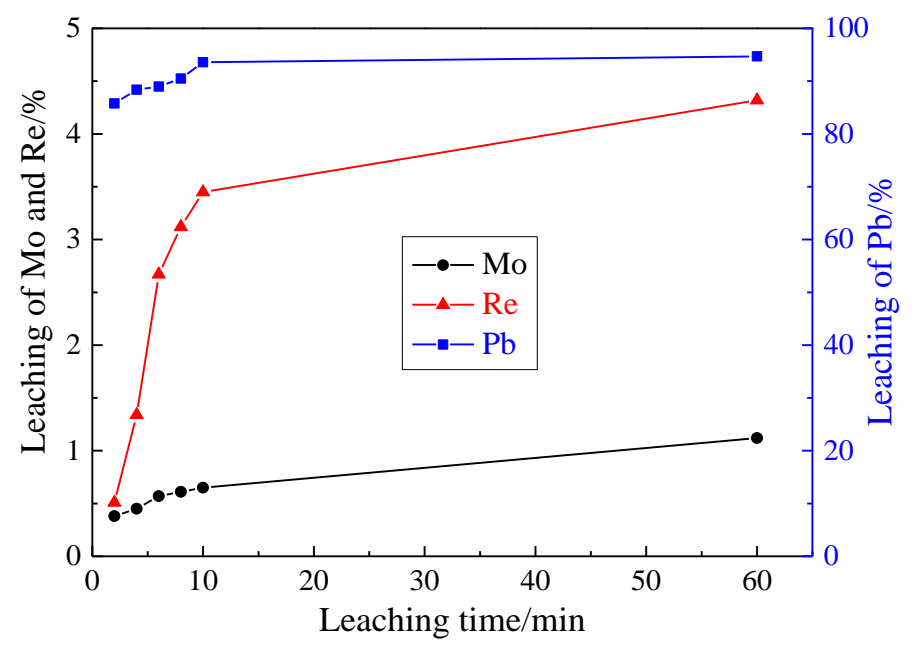

Figure 5. Effect of leaching time on the leaching of $\mathrm{Mo}$, Re and $\mathrm{Pb}$.

\subsubsection{Effect of Liquid-Solid Ratio}

Aiming at optimizing the liquid-solid ratio $(\mathrm{mL} / \mathrm{g})$ for complete removal of $\mathrm{Pb}$, the experiments were performed with the liquid-solid ratio ranging from 2 to 6 . The $\mathrm{HCl}$ concentration, leaching temperature and time were maintained at $8 \mathrm{wt} . \%, 95{ }^{\circ} \mathrm{C}$ and $10 \mathrm{~min}$, respectively. From the results shown in Figure 6, it is ascertained that the removal of $\mathrm{Pb}$ increased significantly from $74.5 \%$ to more than $90 \%$ as the liquid-solid ratio was increased to 5 . The leaching ratio of Re maintained at less than $4 \%$ when the liquid-solid ratio was smaller than 5 and increased distinctly thereafter. However, the leaching ratio of Mo decreased by increasing the liquid-solid ratio up to 5 . Thus, the most suitable liquid-solid ratio was 5 .

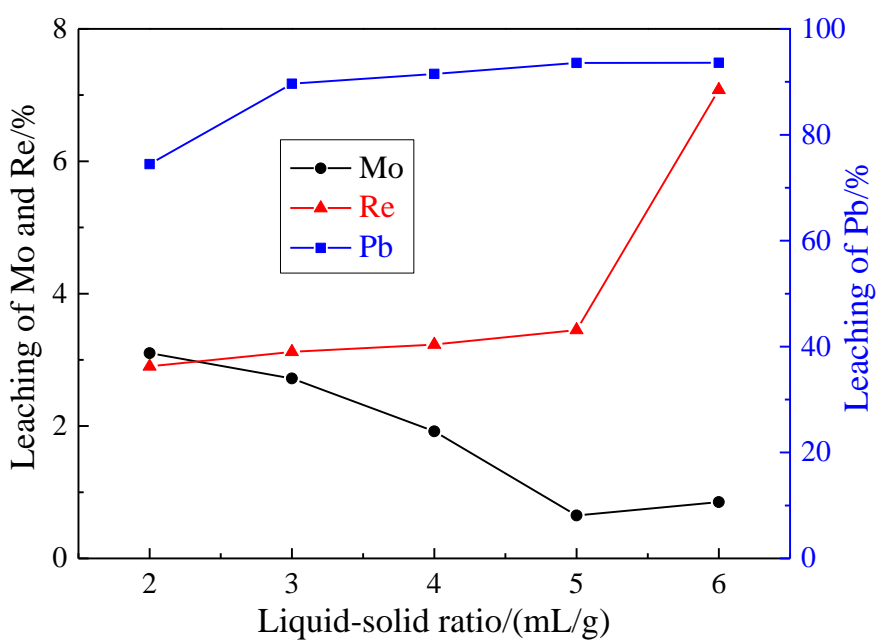

Figure 6. Effect of liquid-solid ratio on the leaching of $\mathrm{Mo}$, Re and $\mathrm{Pb}$. 
From the above analysis, the suitable leaching conditions for removing $\mathrm{Pb}$ are as follows: $\mathrm{HCl}$ concentration of $8 \mathrm{wt}$. \%, leaching temperature of $95^{\circ} \mathrm{C}$, leaching time of $10 \mathrm{~min}$ and liquid-solid ratio of 5. Most of galena (93.6\%) and calcite (97.4\%) were dissolved in the hydrochloric acid. The main chemical composition of molybdenite concentrate after the pretreatment is summarized in Table 2 . It can be observed that Mo and Re were enriched after leaching due to the removal of galena and calcite.

Table 2. Main chemical composition of molybdenite concentrate after pretreatment.

\begin{tabular}{cccccccccccc}
\hline Component & $\mathbf{M o}$ & $\mathbf{R e}$ & $\mathbf{F e}$ & $\mathbf{S i O}_{2}$ & $\mathrm{Al}_{2} \mathbf{O}_{3}$ & $\mathbf{C a O}$ & $\mathbf{M g O}$ & $\mathrm{WO}_{3}$ & $\mathbf{C u}$ & $\mathbf{P b}$ & $\mathbf{S}$ \\
\hline wt. $\%$ & 50.25 & $363 \mathrm{~g} / \mathrm{t}$ & 1.07 & 4.72 & 0.53 & 0.10 & 0.18 & 1.76 & 0.02 & 0.34 & 33.50 \\
\hline
\end{tabular}

\subsection{Separation of Rhenium by Oxidative Roasting}

Oxidative roasting followed by ammonia leaching is the most classical process for recovering Mo and Re from molybdenite concentrate [22,23]. During the oxidative roasting, molybdenum disulfide is oxidized to molybdenum trioxide, which is soluble in the ammonia solution, while rhenium was volatilized into the flue dust in the form of $\mathrm{Re}_{2} \mathrm{O}_{7}$ (whose vapor pressure is $1 \mathrm{~atm}$ at $362{ }^{\circ} \mathrm{C}$ ). In this section, oxidative roasting of the concentrate after acid leaching was conducted to investigate the effect of the pretreatment on the separation of rhenium.

\subsubsection{Effect of Roasting Temperature}

The effect of roasting temperature on the separation of Re is shown in Figure 7. Oxidative roasting was carried out for $120 \mathrm{~min}$ under the air atmosphere. The results in Figure 7 indicate that the volatilization of Re increased slowly and then remained almost constant at temperatures above $550{ }^{\circ} \mathrm{C}$. Almost complete volatilization of rhenium was achieved for the concentrate after pretreatment, $10 \%$ higher than that without pretreatment. This is mainly attributed to the generation of lead molybdate and calcium molybdate in the presence of galena and calcite, which results in serious sintering and restrains the diffusion of $\mathrm{O}_{2}$. Additionally, the formation of perrhenate restricted the Re volatilization [25].

On the contrary, the volatilization of Mo before and after pretreatment gradually increased to $5.3 \%$ and $6.2 \%$, respectively, when the roasting temperature was elevated to $600{ }^{\circ} \mathrm{C}$. Moreover, a further increase in roasting temperature had a significant impact on the Mo volatilization. This is because molybdenum oxides formed during roasting would also partially sublimate even below their melting points. Furthermore, higher temperature accelerated their sublimation. Considering the volatilization of $\mathrm{Re}$, the roasting temperature could be decreased from $600{ }^{\circ} \mathrm{C}$ to $500-550{ }^{\circ} \mathrm{C}$ for the concentrate after pretreatment.

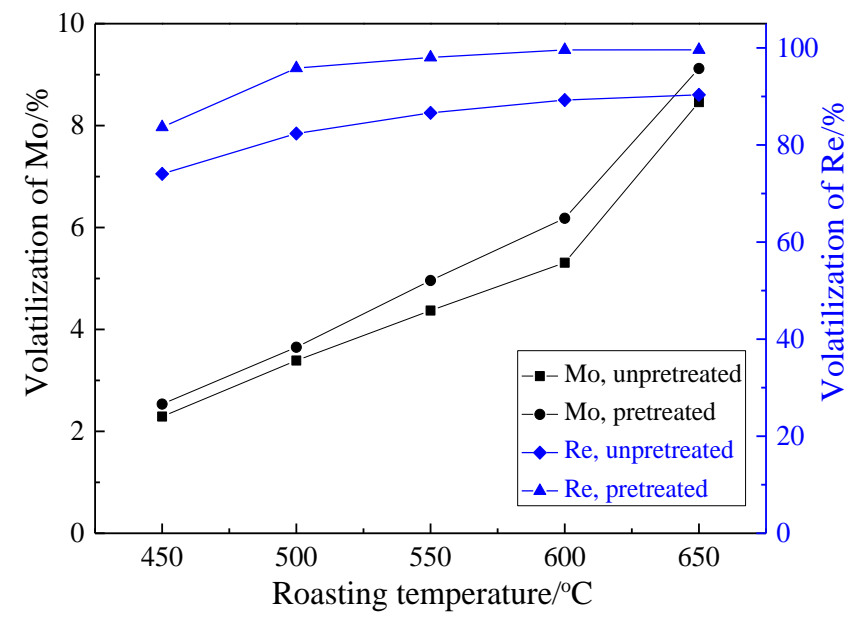

Figure 7. Effect of roasting temperature on the volatilization of Mo and Re. 


\subsubsection{Effect of Roasting Time}

The effect of roasting time on the separation of Re was investigated and the results are shown in Figure 8. The pellets were roasted at $600{ }^{\circ} \mathrm{C}$ (unpretreated) or $550{ }^{\circ} \mathrm{C}$ (pretreated) in air for different time periods from $10 \mathrm{~min}$ to $150 \mathrm{~min}$.

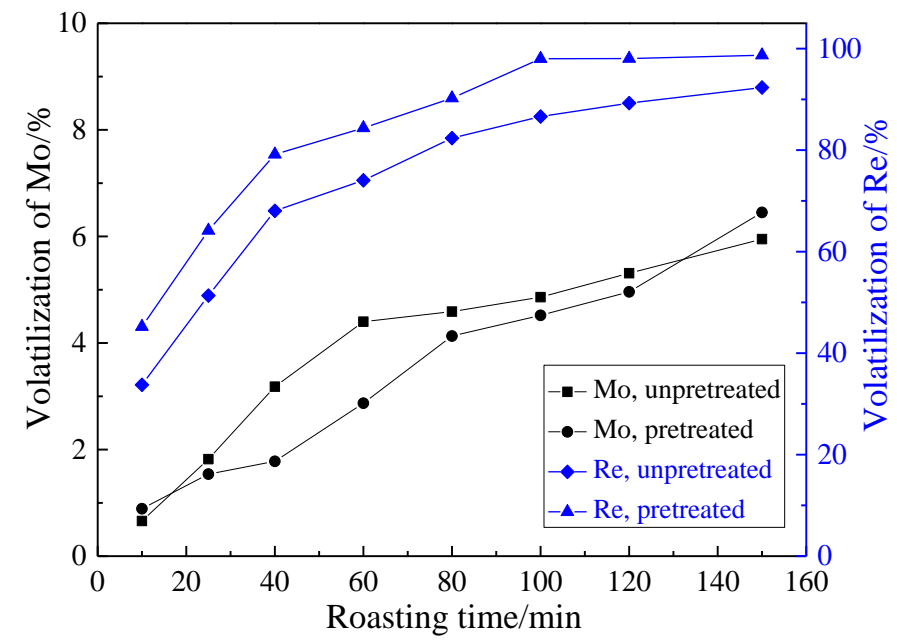

Figure 8. Effect of roasting time on the volatilization of Mo and Re.

It is found that the Mo volatilization increased steadily with increasing roasting time, and the volatilization ratio of Mo in the raw material was greater than that after pretreatment. This is mainly attributed to the higher requrement on the roasting temperature for the raw concentrate.

Similarly, the volatilization ratio of Re increased gradually with the increase of roasting time from $10 \mathrm{~min}$ to $100 \mathrm{~min}$ and then varied slightly. It is also evident that the rhenium volatilization was always higher than that without pretreatment under the experimental conditions. The maximum Re volatilization ratio reached $98.0 \%$ in $100 \mathrm{~min}$, which was greater than that $(86.6 \%)$ for the untreated concentrate. Thus, $100 \mathrm{~min}$ is adequate for roasting the concentrate after hydrochloric acid leaching.

\subsubsection{Effect of $\mathrm{O}_{2}$ Partial Pressure}

The effect of $\mathrm{O}_{2}$ partial pressure $\left(\mathrm{O}_{2} /\left(\mathrm{O}_{2}+\mathrm{N}_{2}\right)\right)$ on the separation of rhenium from molybdenum is shown in Figure 9. The experiments were carried out under the conditions of $600{ }^{\circ} \mathrm{C}, 120 \mathrm{~min}$ (unpretreated) and $550{ }^{\circ} \mathrm{C}, 100 \mathrm{~min}$ (pretreated), respectively. The results in Figure 9 indicate that both the Mo and Re volatilization ratios of the raw concentrate reached their maximum values as the $\mathrm{O}_{2}$ partial pressure was increased to $21 \%$, and then decreased gradually. The sintering phenomenon becomes more serious under higher $\mathrm{O}_{2}$ partial pressure, causing more compact structures of the roasted pellets [25].

After the molybdenite concentrate was pretreated by acid leaching, Mo volatilization kept increasing with increase in the $\mathrm{O}_{2}$ partial pressure. In contrast, the volatilization of Re was improved and then remained nearly stable when the $\mathrm{O}_{2}$ partial pressure exceeded $21 \%$. The maximum $\mathrm{Re}$ volatilization ratio of $98.0 \%$ was obtained at $21 \%$ of $\mathrm{O}_{2}$ partial pressure, while the corresponding Mo volatilization was only $4.5 \%$. Thus, air atmosphere was recommended for oxidative roasting. 


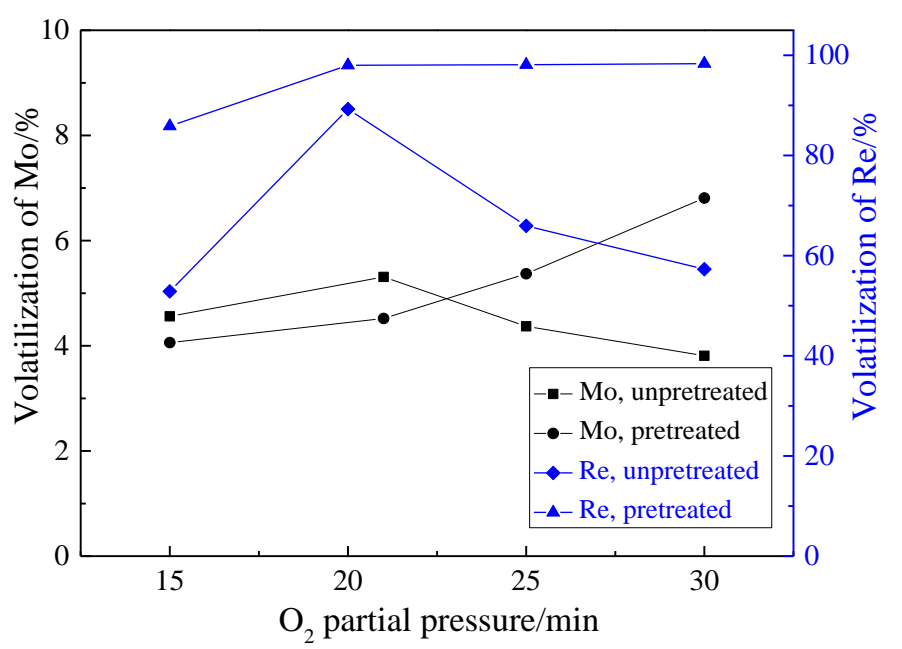

Figure 9. Effect of $\mathrm{O}_{2}$ partial pressure on the volatilization of Mo and Re.

\subsubsection{Phase Transformation in the Roasting Process}

To identify the phase transformation of molybdenite concentrate during oxidative roasting, XRD analysis was performed for determination of the phase compositions of roasted products. The diffractograms of the raw material and roasted products are compared in Figure 10.

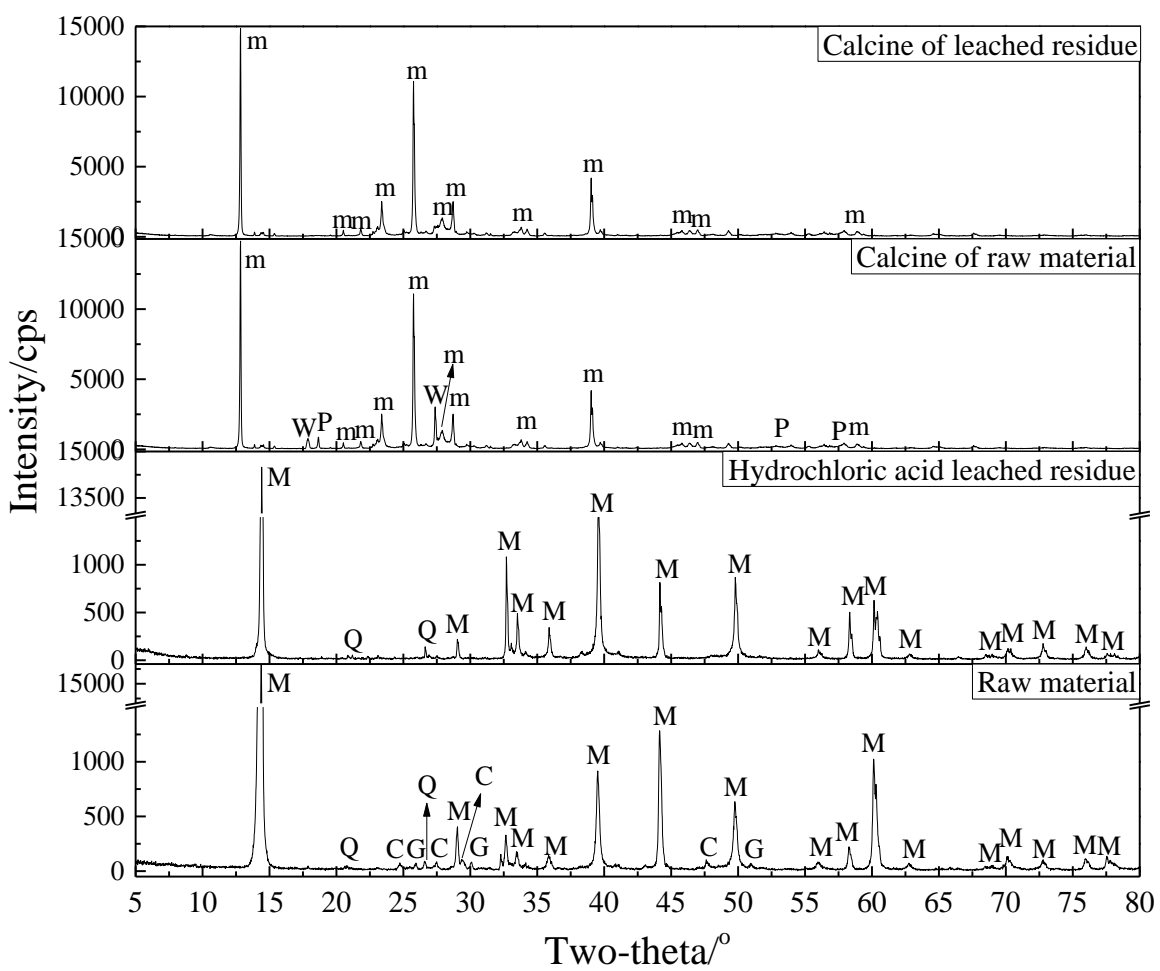

Figure 10. XRD patterns of the molybdenite concentrate and roasted products. (M-Molybdenite, $\mathrm{MoS}_{2} ; \mathrm{G}-$ Galena, $\mathrm{PbS} ; \mathrm{C}-$ Calcite, $\mathrm{CaCO}_{3} ; \mathrm{Q}-\mathrm{Quartz}, \mathrm{SiO}_{2} ; \mathrm{m}-$ Molybdite, $\mathrm{MoO}_{3} ; \mathrm{P}$-Powellite, $\mathrm{CaMoO}_{4} ; \mathrm{W}-$ Wulfenite, $\mathrm{PbMoO}_{4}$ ).

As observed in Figure 10, the diffraction patterns of roasted products are different from that of the raw molybdenite concentrate. Molybdenite $\left(\mathrm{MoS}_{2}\right)$ in the raw material disappeared, whereas molybdite $\left(\mathrm{MoO}_{3}\right)$ was formed according to the following equations [26,27]. Meanwhile, rheniite $\left(\mathrm{ReS}_{2}\right)$ was also oxidized to rhenium (VII) oxide $\left(\operatorname{Re}_{2} \mathrm{O}_{7}\right)$ whose vapor pressure reached $1 \mathrm{~atm}$ at 
$362.4^{\circ} \mathrm{C}$. Thus, rhenium oxide is absent in Figure 10, while molybdite was retained in the calcine during oxidative roasting:

$$
\begin{aligned}
& 2 \mathrm{MoS}_{2}+7 \mathrm{O}_{2} \rightarrow 2 \mathrm{MoO}_{3}+4 \mathrm{SO}_{2} \\
& 4 \mathrm{ReS}_{2}+15 \mathrm{O}_{2} \rightarrow 2 \mathrm{Re}_{2} \mathrm{O}_{7}+8 \mathrm{SO}_{2}
\end{aligned}
$$

By roasting the raw concentrate at $600{ }^{\circ} \mathrm{C}$ for $120 \mathrm{~min}$ under air atmosphere, galena $(\mathrm{PbS})$ was oxidized to lead oxide $(\mathrm{PbO})$, which combined with molybdite to form wulfenite $\left(\mathrm{PbMoO}_{4}\right)$. In the meantime, calcite $\left(\mathrm{CaCO}_{3}\right)$ in the raw material was decomposed to calcium oxide $(\mathrm{CaO})$. Similarly, $\mathrm{CaO}$ would also react with molybdite to generate powellite $\left(\mathrm{CaMoO}_{4}\right)$, as described by the following equations:

$$
\begin{gathered}
2 \mathrm{PbS}+3 \mathrm{O}_{2} \rightarrow 2 \mathrm{PbO}+2 \mathrm{SO}_{2} \\
\mathrm{PbO}+\mathrm{MoO}_{3} \rightarrow \mathrm{PbMoO}_{4} \\
\mathrm{CaCO}_{3} \rightarrow \mathrm{CaO}+\mathrm{CO}_{2} \\
\mathrm{CaO}+\mathrm{MoO}_{3} \rightarrow \mathrm{CaMoO}_{4}
\end{gathered}
$$

As a result of hydrochloric acid leaching, the peaks of galena and calcite were disappeared. No obvious diffraction peaks of wulfenite and powellite except those of molybdite are observed in the XRD pattern of the roasted product, which was obtained at $550{ }^{\circ} \mathrm{C}$ for $100 \mathrm{~min}$ under air atmosphere.

To evaluate the effect of removing lead and calcium on the leaching of Mo, the roasted products were leached at $60{ }^{\circ} \mathrm{C}$ for $3 \mathrm{~h}$ with $7 \mathrm{~mol} / \mathrm{L}$ aqueous ammonium solution and liquid-solid ratio of 10 [4]. The results indicate that only $79.3 \%$ Mo was leached from the calcine of molybdenite concentrate without pretreatment. In contrast, the Mo leaching ratio reached $91.5 \%$ for the calcine of concentrate pretreated by acid leaching. This is attributed to the elimination of adverse effects of molybdates, which were insoluble in the aqueous ammonium solution. From the above results, it can be concluded that acid leaching as a method of molybdenite concentrate pretreatment not only played a significant role in improving the Re volatilization, but also had a crucial impact on the subsequent leaching of Mo.

\section{Conclusions}

Separation of rhenium from a kind of lead-rich molybdenite concentrate by oxidative roasting was studied. The volatilization of Re and leaching ratio of Mo in ammonia solution were improved significantly after the lead and calcium components in the raw material were removed by hydrochloric acid. The results of acid leaching show that $93.6 \%$ of $\mathrm{Pb}$ and $97.4 \%$ of $\mathrm{Ca}$ were removed under the conditions of $95{ }^{\circ} \mathrm{C}$ for $10 \mathrm{~min}$ with $\mathrm{HCl}$ concentration of $8 \mathrm{wt}$. \% and liquid-solid ratio of $5(\mathrm{~mL} / \mathrm{g})$. The oxidative roasting experiment indicates the rhenium volatilization of $89.3 \%$ was obtained for the raw concentrate when roasted at $600{ }^{\circ} \mathrm{C}$ for $120 \mathrm{~min}$ in air. In contrast, the rhenium volatilization was enhanced distinctly to $98.0 \%$ when the pretreated concentrate was roasted at $550{ }^{\circ} \mathrm{C}$ for $100 \mathrm{~min}$. Furthermore, the molybdenum leaching ratio of $91.5 \%$ was achieved by leaching the calcine of pretreated concentrate in aqueous ammonia solution. Conversely, only $79.3 \%$ of Mo was leached from the calcine of molybdenite concentrate without pretreatment. The XRD analysis confirms that the formation of molybdates was adverse for the rhenium separation and the subsequent leaching of molybdenum, which can be prevented after acid pretreatment.

Acknowledgments: This work was partially supported by the Co-Innovation Center for Clean and Efficient Utilization of Strategic Metal Mineral Resources, the Shenghua Lieying Program of Central South University under Grant 502035001, and the Innovation-Driven Program of Central South University under Grant 2016CXS021.

Author Contributions: Guanghui Li and Zhiwei Peng conceived and designed and performed the experiments; Zhixiong You, Hu Sun and Rong Sun performed the experiments, analyzed the data and wrote the paper; Yuanbo Zhang and Tao Jiang supervised experimental work and reviewed the manuscript.

Conflicts of Interest: The authors declare no conflict of interest. 


\section{References}

1. Hu, K.; Zhao, D.; Liu, J. Synthesis of nano- $\mathrm{MoS}_{2}$ /bentonite composite and its application for removal of organic dye. Trans. Nonferr. Met. Soc. 2012, 22, 2484-2490. [CrossRef]

2. U.S. Geological Survey. Minerals Commodity Summaries (2015) and Minerals Yearbook (2012). Available online: http://minerals.usgs.gov/minerals/pubs/commodity/rhenium/mcs-2012-rheni.pdf (accessed on 23 March 2015).

3. Mccandless, T.; Ruiz, J.; Campbell, A. Rhenium behavior in molybdenite in hypogene and near-surface environments: Implications for Re-Os geochronometry. Geochim. Cosmochim. Acta 1993, 57, 889-905. [CrossRef]

4. Xiang, T. Molybdenum Metallurgy; Central South University Press: Changsha, China, 2002; pp. $23-34$. (In Chinese)

5. Tarasov, A.; Besser, A.; Gedgagov, E. Integrated technology for processing rhenium-containing molybdenite concentrates to recover molybdenum and rhenium into commercial products. Miner. Process. Extr. Metall. Rev. 2001, 22, 509-517. [CrossRef]

6. Shariat, M.; Hassani, M. Rhenium recovery from Sarcheshmeh molybdenite concentrate. J. Mater. Process. Technol. 1998, 74, 243-250. [CrossRef]

7. Tripathy, P.; Rakhasia, R. Chemical processing of a low grade molybdenite concentrate to recover molybdenum. Trans. Inst. Min. Metall. Sect. C 2006, 115, 8-14. [CrossRef]

8. Juneja, J.; Singh, S.; Bose, D. Investigations on the extraction of molybdenum and rhenium values from low grade molybdenite concentrate. Hydrometallurgy 1996, 41, 201-209. [CrossRef]

9. Ketcham, V.; Hazen, W.; Coltrinari, E. Pressure oxidation process for the production of molybdenum trioxide from molybdenite. U.S. Patent US614988321, November 2000.

10. Khoshnevisan, A.; Yoozbashizadeh, H.; Mozammel, M.; Sadrnezhaad, S. Kinetics of pressure oxidative leaching of molybdenite concentrate by nitric acid. Hydrometallurgy 2012, 111-112, 52-57. [CrossRef]

11. Jiang, K.; Wang, Y.; Zou, X.; Zhang, L.; Liu, S. Extraction of molybdenum from molybdenite concentrates with hydrometallurgical processing. JOM 2012, 64, 1285-1289. [CrossRef]

12. Joo, S.; Kim, Y.; Kang, J.; Yoon, H.; Kim, D.; Shin, S. Recovery of molybdenum and rhenium using selective precipitation method from molybdenite roasting dust in alkali leaching solution. Mater. Trans. 2012, 53, 2038-2042. [CrossRef]

13. Cao, Z.; Zhong, H.; Liu, G.; Fu, J.; Wang, S.; Qiu, Y. Electric-oxidation kinetics of molybdenite concentrate in acidic $\mathrm{NaCl}$ solution. Can. J. Chem. Eng. 2009, 87, 939-944.

14. Molaei, R.; Shariat, M.; Zakeri, A.; Boutorabi, M. Rhenium (VII) recovery via electro-oxidation process I. The influence of time, temperature, and pH. Electrochem. Solid. St. Lett. 2011, 14, E1-E3. [CrossRef]

15. Askari Zamani, M.; Hiroyoshi, N.; Tsunekawa, M.; Vaghar, R.; Oliazadeh, M. Bioleaching of Sarcheshmeh molybdenite concentrate for extraction of rhenium. Hydrometallurgy 2005, 80, 23-31. [CrossRef]

16. Olson, G.; Clark, T. Bioleaching of molybdenite. Hydrometallurgy 2008, 93, 10-15. [CrossRef]

17. Peng, Z.; Hwang, J. Microwave-assisted metallurgy. Int. Mater. Rev. 2015, 60, 30-63. [CrossRef]

18. Joo, S.; Kim, Y.; Kang, J.; Kumar, J.; Yoon, H.; Parhi, P. Recovery of rhenium and molybdenum from molybdenite roasting dust leaching solution by ion exchange resins. Mater. Trans. 2012, 53, 2034-2037. [CrossRef]

19. Lan, X.; Liang, S.; Song, Y. Recovery of rhenium from molybdenite calcine by a resin-in-pulp process. Hydrometallurgy 2006, 82, 133-136. [CrossRef]

20. Seo, S.; Choi, W.; Yang, T.; Kim, M.; Tran, T. Recovery of rhenium and molybdenum from a roaster fume scrubbing liquor by adsorption using activated carbon. Hydrometallurgy 2015, 129-130, 145-150. [CrossRef]

21. Keshavarz Alamdari, E.; Darvishi, D.; Haghshenas, D.; Yousefi, N.; Sadrnezhaad, S. Separation of Re and Mo from roasting-dust leach-liquor using solvent extraction technique by TBP. Sep. Purif. Technol. 2012, 86, 143-148. [CrossRef]

22. Marin, T.; Utigard, T.; Hernandez, C. Roasting kinetics of molybdenite concentrates. Can. Metall. Q. 2009, 48, 73-80. [CrossRef]

23. Mchugh, L.; Balliett, R.; Mozolic, J. The sulfide ore looping oxidation process: An alternative to current roasting and smelting practice. JOM 2008, 60, 84-87. [CrossRef] 
24. Kim, B.; Lee, H.; Choi, Y.; Kim, S. Kinetics of the oxidative roasting of low grade Mongolian molybdenite concentrate. Mater. Trans. 2009, 50, 2669-2674. [CrossRef]

25. Wang, L.; Zhang, G.; Dang, J.; Chou, K. Oxidation roasting of molybdenite concentrate. Trans. Nonferr. Met. Soc. 2015, 25, 4167-4174. [CrossRef]

26. Shigegaki, Y.; Basu, S.; Wakihara, M.; Taniguchi, M. Thermal analysis and kinetics of oxidation of molybdenum sulfides. J. Therm. Anal. Calorim. 1988, 34, 1427-1440. [CrossRef]

27. Utigard, T. Oxidation mechanism of molybdenite concentrate. Metall. Mater. Trans. B 2009, 40, 490-496. [CrossRef]

28. Ma, G.; Lei, N.; Wang, Z.; Wang, W.; Feng, B. Research on reducing the lead content of high-lead molybdenite concentrates. China Molybd. Ind. 2015, 39, 23-25. (In Chinese)

29. Gupta, C. Extractive Metallurgy of Molybdenum; CRC Press: Boca Raton, FL, USA, 1992; pp. 156-157.

30. Holdich, R.; Lawson, G. The solubility of aqueous lead chloride solutions. Hydrometallurgy 1987, 19, 199-208. [CrossRef]

(C) 2016 by the authors; licensee MDPI, Basel, Switzerland. This article is an open access article distributed under the terms and conditions of the Creative Commons Attribution (CC-BY) license (http://creativecommons.org/licenses/by/4.0/). 